\title{
KINEMATIC ANALYSIS OF TRICEPT PARALLEL MANIPULATOR
}

\author{
Mir Amin HosSeini ${ }^{1}$ ANd HAMId-REza MOHAMmadai Daniali ${ }^{2}$ \\ ${ }^{I}$ Department of Mechanical Engineering, Islamic Azad University, \\ Ayatollah Amoli Branch, Amol, Iran. \\ ${ }^{2}$ Department of Mechanical Engineering, \\ Babol University of Technology, \\ Babol, Iran.
}

Ma.hosseini@iauamol.ac.ir; mohammadi@nit.ac.ir

\begin{abstract}
Parallel manipulators consist of fixed and moving platforms connected to each other with some actuated links. They have some significant advantages over their serial counterparts. While, they suffer from relatively small workspaces, complex kinematics relations and highly singular points within their workspaces. In this paper, forward kinematics of Tricept parallel manipulator is solved analytically and its workspace optimization is performed. This parallel manipulator has a complex degree of freedom, therefore leads to dimensional in-homogeneous Jacobian matrices. Thus, we divide some entries of the Jacobian by units of length, thereby producing a new Jacobian that is dimensionally homogeneous. Moreover, its workspace is parameterized using some design parameters. Then, using GA method, the workspace is optimized subjects to some geometric constraints. Finally, dexterity of the design is evaluated.
\end{abstract}

ABSTRAK: Manipulator selari terdiri daripada platform tetap dan bergerak yang bersambung antara satu sama lain dengan beberapa pautan bergerak. Manipulator selari mempunyai beberapa kebaikan tertentu dibandingkan dengan yang bersamaan dengannya. Walaupun ia mempunyai ruang kerja yang sempit, hubungan kinematik kompleks dan titik tunggal tinggi dalam linkungan ruang kerjanya. Dalam kajian ini, kinematik ke hadapan manipulator selari Tricept diselesaikan secara analisa dan pengoptimuman ruang kerja dijalankan. Manipulator selari ini mempunyai darjah kebebasan yang kompleks, yang menyebabkan ia mendorong kepada kehomogenan dimensi matriks Jacobian. Catatan Jacobian dibahagikan kepada unit panjang, dimana ia menghasilkan Jacobian baru yang homogen dimensinya. Tambahan, ruang kerjanya diparameterkan dengan menggunakan beberapa parameter reka bentuk. Kemudian, dengan kaedah GA, ruang kerja mengoptimakan subjek kepada beberapa kekangan geometrik. Akhirnya, kecakatan reka bentuk dinilaikan.

KEYWORDS: kinematic; workspace; singularity; tricept

\section{INTRODUCTION}

Parallel manipulators are closed-loop mechanisms and consist of two main elements coupled through several limbs acting in parallel. One body is designated as fixed and is called base, while the other is regarded as movable and hence is called moving platform or end-effector (EE) of the manipulator. Typically, the number of actuators is equal to the number of degrees of freedom (DOF) of the manipulator.

Parallel manipulators have some significant advantages over their serial counterparts, such as more rigidity and accuracy, higher force and torque capacity and higher speed [1, 
2]. On the other hand, they suffer from relatively small workspaces, complex kinematics relations and highly singular points within their workspaces.

Choosing a set of geometric parameters so as to achieve optimal performance is of vital significance in robotics research. Among all kinematic measures, workspace is the most important index in the design of a parallel manipulator. In this paper, the workspace of Tricept is parameterized using some design parameters. Moreover, some geometric constraints are considered in the problem. Because of nonlinear discontinuous behavior of the problem, GA is used here to optimize the workspace [3]. For the workspace of the manipulator, we evaluate local conditioning indices of the Jacobian matrices, as well.

This paper is organized as follows. As a case study, for Tricept parallel manipulator with both rotational and translational DOF, forward and inverse kinematics are derived analytically. Moreover, Its Jacobian matrix is derived and its singularity is studied. Finally, we optimize the workspace of the manipulator and evaluate its local conditioning index as a measure of dexterity.

\section{TRICEPT PARALLEL MANIPULATOR}

Tricept parallel manipulator, as depicted in Fig. 1, with two rotational and one translational DOF was introduced by Neumann [4]. Siciliano [5] studied the inverse kinematics and manipulability of Tricept.

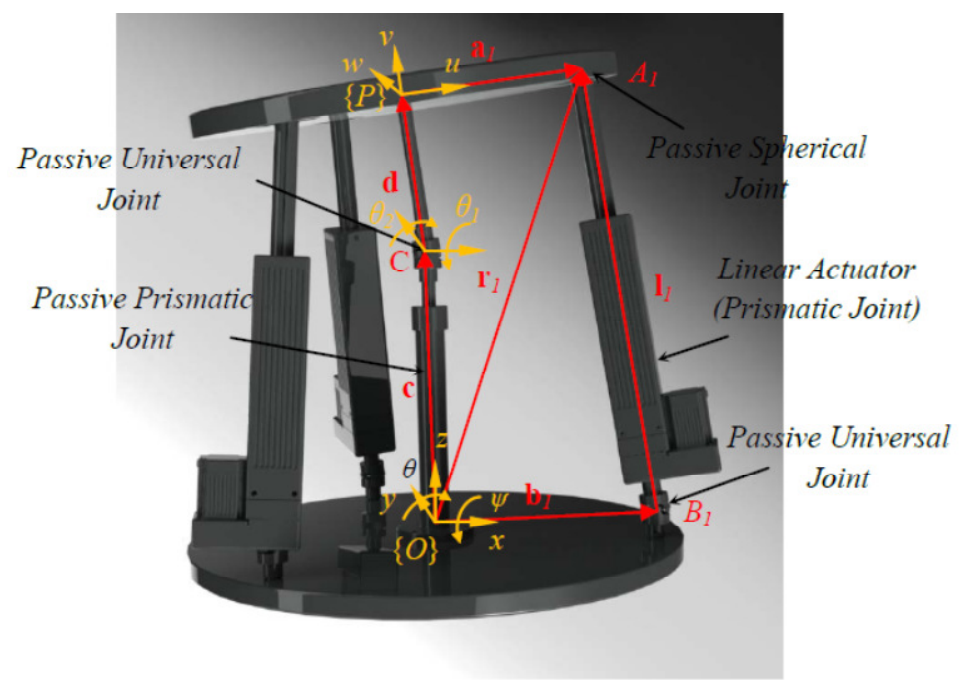

Fig. 1: Tricept Manipulator.

The manipulator has three actuated limbs which connect the base to the moving platform. Each of these limbs consists of a spherical - prismatic - spherical (SPS) kinematic chain, where only the prismatic joint is actuated. Alternatively, one of the spherical joints can be replaced by a universal joint with no side effect on the kinematic equations. In either case, as each of the actuated limbs has mobility of at least 6-DOF, a passive prismatic-universal (PU) limb exists at the centre of the mechanism to constrain the mobility of the moving platform to 3-DOF. When the moving platform is parallel to the base, the two revolute axes of the universal joint of the centre passive limb, are parallel with the base frame's $x$ and $y$-axes. 
Moving and global frames, namely; $\{P(u v w)\}$ and $\{O(x y z)\}$, are attached to the moving and base platforms, respectively.

\subsection{Inverse Kinematic}

Inverse kinematic problem is stated as: given a desired pose of the EE find the actuator lengths. Considering Fig. 1, one can write the following, in which the columns of the matrix are the position vectors of the spherical joints:

$$
\begin{aligned}
& \mathbf{A}=\left[\begin{array}{ccc}
\mathrm{C} \theta & \mathrm{S} \psi \mathrm{S} \theta & \mathrm{C} \psi \mathrm{S} \theta \\
0 & \mathrm{C} \psi & -\mathrm{S} \psi \\
-\mathrm{S} \theta & \mathrm{C} \theta \mathrm{S} \psi & \mathrm{C} \theta \mathrm{C} \psi
\end{array}\right]\left[\begin{array}{ccc}
a / \sqrt{3} & -a / 2 \sqrt{3} & -a / 2 \sqrt{3} \\
0 & a / 2 & -a / 2 \\
d & d & d
\end{array}\right]+\left[\begin{array}{ccc}
0 & 0 & 0 \\
0 & 0 & 0 \\
c & c & c
\end{array}\right] \\
& =\left[\begin{array}{ccc}
a / \sqrt{3} \mathrm{C} \theta+d \mathrm{C} \psi \mathrm{S} \theta & -a / 2 \sqrt{3} \mathrm{C} \theta+a / 2 \mathrm{~S} \psi \mathrm{S} \theta+d \mathrm{C} \psi \mathrm{S} \theta & -a / 2 \sqrt{3} \mathrm{C} \theta-a / 2 \mathrm{~S} \psi \mathrm{S} \theta+d \mathrm{C} \psi \mathrm{S} \theta \\
-d \mathrm{~S} \psi & a / 2 \mathrm{C} \psi-d \mathrm{~S} \psi & -a / 2 \mathrm{C} \psi-d \mathrm{~S} \psi \\
-a / \sqrt{3} \mathrm{~S} \theta+d \mathrm{C} \theta \mathrm{C} \psi+c & a / 2 \sqrt{3} \mathrm{~S} \theta+a / 2 \mathrm{C} \theta \mathrm{S} \psi+d \mathrm{C} \theta \mathrm{C} \psi+c & a / 2 \sqrt{3} \mathrm{~S} \theta-a / 2 \mathrm{C} \theta \mathrm{S} \psi+d \mathrm{C} \theta \mathrm{C} \psi+c
\end{array}\right]
\end{aligned}
$$

where a is the moving platforms radius. Moreover, $C$ and $S$ stand for the Cos and Sin functions, respectively; $\mathrm{c}$ is the length of the passive prismatic actuator of the middle limb.

The position vectors of the universal joints are grouped in the columns of matrix B as:

$$
\mathbf{B}=\left[\begin{array}{ccc}
b / \sqrt{3} & -b / 2 \sqrt{3} & -b / 2 \sqrt{3} \\
0 & b / 2 & -b / 2 \\
0 & 0 & 0
\end{array}\right]
$$

in which $b$ is the radius of the base platform.

According to eqs. (1) and (2) the actuator lengths can be calculated as the followings:

$$
\begin{aligned}
q_{1}^{2}= & \frac{a^{2}}{3}+\frac{b^{2}}{3}+c^{2}+d^{2}-\frac{2}{3} a b C \theta+2 c d C \theta C \psi-\frac{2 b d}{\sqrt{3}} C \psi S \theta \\
q_{2}^{2}= & \frac{a^{2}}{3}+\frac{b^{2}}{3}+c^{2}+d^{2}-\frac{1}{2} a b\left(\frac{1}{3} C \theta-\frac{1}{\sqrt{3}} S \psi S \theta+C \psi\right)+b d\left(\frac{C \psi S \theta}{\sqrt{3}}+S \psi\right) \\
& +2 c d C \theta C \psi+a c\left(\frac{S \theta}{\sqrt{3}}+C \theta S \psi\right) \\
q_{3}^{2}= & \frac{a^{2}}{3}+\frac{b^{2}}{3}+c^{2}+d^{2}-\frac{1}{2} a b\left(\frac{1}{3} C \theta+\frac{1}{\sqrt{3}} S \psi S \theta+C \psi\right)+b d\left(\frac{C \psi S \theta}{\sqrt{3}}-S \psi\right) \\
& +2 c d C \theta C \psi+a c\left(\frac{S \theta}{\sqrt{3}}-C \theta S \psi\right)
\end{aligned}
$$

\subsection{Forward kinematic}

Forward kinematic is stated as: given a set of actuator lengths find the pose of the EE. In eqs.(3-5), we substitute now the equivalent expressions for $S \psi$ and $C \psi$ given below:

$$
\begin{aligned}
& t_{2}=\tan \left(\frac{\psi}{2}\right) \\
& S \psi=\frac{2 t_{2}}{1+t^{2}{ }_{2}}
\end{aligned}
$$




$$
C \psi=\frac{1-t_{2}^{2}}{1+t_{2}^{2}}
$$

Similarly, equivalent expressions for $S \theta$ and $C \theta$ yields:

$$
\begin{aligned}
& t_{1}=\tan \left(\frac{\theta}{2}\right) \\
& S \theta=\frac{2 t_{1}}{1+t^{2}{ }_{1}} \\
& C \theta=\frac{1-t^{2}{ }_{1}}{1+t^{2}}
\end{aligned}
$$

Substituting the values of $S \psi, C \psi, S \theta$ and $C \theta$ from eqs.(6-11) into eqs.(3-5), upon simplifications leads to the following equations for the limbs;

$$
M_{i} \mathrm{t}_{2}{ }_{2}+N_{i} \mathrm{t}_{2}+L_{i}=0 ; \text { for } \mathrm{i}=1,2,3
$$

In which the parameters for the three limbs are defined as:

$$
\begin{aligned}
M_{1}= & \left(\frac{1}{1+t_{1}^{2}}\right)\left[\left(t_{1}^{2}\right)\left(\frac{a^{2}}{3}+\frac{b^{2}}{3}+c^{2}+d^{2}-q_{1}^{2}+\frac{2}{3} a b+2 c d\right)+\right. \\
& \left.\left(t_{1}\right)\left(\frac{4 b d}{\sqrt{3}}\right)+\left(\frac{a^{2}}{3}+\frac{b^{2}}{3}+c^{2}+d^{2}-q_{1}^{2}-\frac{2}{3} a b-2 c d\right)\right] \\
N_{1}= & 0 \\
L_{1}= & \left(\frac{1}{1+t_{1}^{2}}\right)\left[\left(t_{1}^{2}\right)\left(\frac{a^{2}}{3}+\frac{b^{2}}{3}+c^{2}+d^{2}-q_{1}^{2}+\frac{2}{3} a b-2 c d\right)+\right. \\
& \left.\left(t_{1}\right)\left(\frac{-4 b d}{\sqrt{3}}\right)+\left(\frac{a^{2}}{3}+\frac{b^{2}}{3}+c^{2}+d^{2}-q_{1}^{2}-\frac{2}{3} a b+2 c d\right)\right] \\
M_{2}= & \left(\frac{1}{1+t_{1}^{2}}\right)\left[\left(t_{1}^{2}\right)\left(\frac{a^{2}}{3}+\frac{b^{2}}{3}+c^{2}+d^{2}-q_{2}^{2}+\frac{2}{3} a b+2 c d\right)+\right. \\
& \left.\left(t_{1}\right)\left(\frac{2 a c-2 b d}{\sqrt{3}}\right)+\left(\frac{a^{2}}{3}+\frac{b^{2}}{3}+c^{2}+d^{2}-q_{2}^{2}+\frac{1}{3} a b-2 c d\right)\right] \\
N_{2}= & \left(\frac{1}{1+t_{1}^{2}}\right)\left[\left(t_{1}^{2}\right)(2 b d-2 a c)+\left(t_{1}\right)\left(\frac{2 a b}{\sqrt{3}}\right)+(2 b d+2 a c)\right] \\
L_{2}= & \left(\frac{1}{1+t_{1}^{2}}\right)\left[\left(t_{1}^{2}\right)\left(\frac{a^{2}}{3}+\frac{b^{2}}{3}+c^{2}+d^{2}-q_{2}^{2}-\frac{1}{3} a b-2 c d\right)+\right. \\
& \left.\left(t_{1}\right)\left(\frac{2 a c+2 b d}{\sqrt{3}}\right)+\left(\frac{a^{2}}{3}+\frac{b^{2}}{3}+c^{2}+d^{2}-q_{2}^{2}-\frac{2}{3} a b+2 c d\right)\right] \\
M_{3}= & \left(\frac{1}{1+t_{1}^{2}}\right)\left[\left(t_{1}^{2}\right)\left(\frac{a^{2}}{3}+\frac{b^{2}}{3}+c^{2}+d^{2}-q_{3}^{2}+\frac{2}{3} a b+2 c d\right)+\right. \\
& \left.\left(t_{1}\right)\left(\frac{2 a c-2 b d}{\sqrt{3}}\right)+\left(\frac{a^{2}}{3}+\frac{b^{2}}{3}+c^{2}+d^{2}-q_{2}^{2}+\frac{1}{3} a b-2 c d\right)\right] \\
N_{3}= & \left(\frac{1}{1+t_{1}^{2}}\right)\left[\left(t_{1}^{2}\right)(-2 b d+2 a c)+\left(t_{1}\right)\left(\frac{-2 a b}{\sqrt{3}}\right)+(-2 b d-2 a c)\right]
\end{aligned}
$$




$$
\begin{aligned}
L_{3}= & \left(\frac{1}{1+t_{1}^{2}}\right)\left[\left(t_{1}^{2}\right)\left(\frac{a^{2}}{3}+\frac{b^{2}}{3}+c^{2}+d^{2}-q_{3}^{2}-\frac{1}{3} a b-2 c d\right)+\right. \\
& \left.\left(t_{1}\right)\left(\frac{2 a c+2 b d}{\sqrt{3}}\right)+\left(\frac{a^{2}}{3}+\frac{b^{2}}{3}+c^{2}+d^{2}-q_{2}^{2}-\frac{2}{3} a b+2 c d\right)\right]
\end{aligned}
$$

Subtracting a ratio of equations (12) for the second and the third limbs leads to;

$$
\begin{aligned}
& M_{3}\left(M_{2} t_{2}^{2}+N_{2} t_{2}+L_{2}\right)-M_{2}\left(M_{3} t^{2}{ }_{2}+N_{3} t_{2}+L_{3}\right)=0 \\
& L_{3}\left(M_{2} t^{2}{ }_{2}+N_{2} t_{2}+L_{2}\right)-L_{2}\left(M_{3} t^{2}{ }_{2}+N_{3} t_{2}+L_{3}\right)=0
\end{aligned}
$$

Then, one can write:

$$
\left[\begin{array}{cc}
M_{3} N_{2}-M_{2} N_{3} & M_{3} L_{2}-M_{2} L_{3} \\
L_{3} M_{2}-L_{2} M_{3} & L_{3} N_{2}-L_{2} N_{3}
\end{array}\right]\left[\begin{array}{c}
t_{2} \\
1
\end{array}\right]=\left[\begin{array}{l}
0 \\
0
\end{array}\right]
$$

Eliminating $t_{2}$ from the foregoing equation yields:

$$
\left(M_{3} N_{2}-M_{2} N_{3}\right)\left(L_{3} N_{2}-L_{2} N_{3}\right)+\left(M_{3} L_{2}-M_{2} L_{3}\right)^{2}=0
$$

Recalling the above process for the first and the second limbs; the third and the first limbs lead to the following equations, respectively;

$$
\begin{aligned}
& \left(M_{2} N_{1}-M_{1} N_{2}\right)\left(L_{2} N_{1}-L_{1} N_{2}\right)+\left(M_{2} L_{1}-M_{1} L_{2}\right)^{2}=0 \\
& \left(M_{3} N_{1}-M_{1} N_{3}\right)\left(L_{3} N_{1}-L_{1} N_{3}\right)+\left(M_{3} L_{1}-M_{1} L_{3}\right)^{2}=0
\end{aligned}
$$

Equations (25-27) are univariate polynomials of degree eight and can be solved for $t_{1}$. The common roots of these equations are the solutions sought.

\section{JACOBIAN AND SINGULARITY ANALYSIS}

\subsection{Jacobian Matrix}

Generally, the EE twist array and the actuators velocity vector are related as:

$$
\mathbf{J}_{x} \dot{\mathbf{x}}=\mathbf{J}_{q} \dot{\mathbf{q}}
$$

in which $\mathbf{J}_{\mathrm{x}}$ and $\mathbf{J}_{\mathrm{q}}$ are the Jacobians; $\dot{\mathbf{x}}$ is the three dimensional twist array; $\dot{\mathbf{q}}$ is the three dimensional actuator velocity vector as:

$$
\begin{aligned}
& \dot{\mathbf{x}}=\left[\begin{array}{lll}
\dot{c} & \dot{\psi} & \dot{\theta}
\end{array}\right]^{\mathrm{T}} \\
& \dot{\mathbf{q}}=\left[\begin{array}{lll}
l_{1} & l_{2} & l_{3}
\end{array}\right]^{\mathrm{T}}
\end{aligned}
$$

Taking the first time derivatives of the $\mathrm{i}^{\text {th }}$ limb vector close loop equation [5], yields;

$$
\mathbf{n}_{l i}{ }^{\mathrm{T}} \dot{\mathbf{c}}+\mathbf{n}_{l i}{ }^{\mathrm{T}} \boldsymbol{\omega}_{p} \times\left(\mathbf{R}\left(\mathbf{a}_{i}+\mathbf{d}\right)\right)=\dot{l}_{i}
$$

Rewriting the above equation for the three limbs leads to: 


$$
\left[\begin{array}{lll}
n_{112} & \left(\mathbf{R}\left(\mathbf{a}_{1}+\mathbf{d}\right) \times \mathbf{n}_{11}\right)_{x} & \left(\mathbf{R}\left(\mathbf{a}_{1}+\mathbf{d}\right) \times \mathbf{n}_{11}\right) \\
n_{12 z} & \left(\mathbf{R}\left(\mathbf{a}_{2}+\mathbf{d}\right) \times \mathbf{n}_{\mathrm{B}}\right)_{x} & \left(\mathbf{R}\left(\mathbf{a}_{2}+\mathbf{d}\right) \times \mathbf{n}_{\mathrm{B}}\right) \\
n_{132} & \left(\mathbf{R}\left(\mathbf{a}_{3}+\mathbf{d}\right) \times \mathbf{n}_{\mathrm{B}}\right)_{x} & \left(\mathbf{R}\left(\mathbf{a}_{3}+\mathbf{d}\right) \times \mathbf{n}_{\mathrm{B}}\right)_{y}
\end{array}\right]\left[\begin{array}{c}
\dot{c} \\
\dot{\psi} \\
\dot{\theta}
\end{array}\right]=\left[\begin{array}{c}
i_{1} \\
\dot{l}_{2} \\
\dot{l}_{3}
\end{array}\right]
$$

Therefore, this equation can be written as a more general form of eq.(28), in which:

$$
\begin{aligned}
& \mathbf{J}_{x}=\left[\begin{array}{lll}
n_{11 z} & \left(\mathbf{R}\left(\mathbf{a}_{1}+\mathbf{d}\right) \times \mathbf{n}_{11}\right)_{x} & \left(\mathbf{R}\left(\mathbf{a}_{1}+\mathbf{d}\right) \times \mathbf{n}_{\mathrm{11}}\right)_{y} \\
n_{12 z} & \left(\mathbf{R}\left(\mathbf{a}_{2}+\mathbf{d}\right) \times \mathbf{n}_{12}\right)_{x} & \left(\mathbf{R}\left(\mathbf{a}_{2}+\mathbf{d}\right) \times \mathbf{n}_{12}\right)_{y} \\
n_{13 z} & \left(\mathbf{R}\left(\mathbf{a}_{3}+\mathbf{d}\right) \times \mathbf{n}_{1 \mathrm{~B}}\right)_{x} & \left(\mathbf{R}\left(\mathbf{a}_{3}+\mathbf{d}\right) \times \mathbf{n}_{13}\right)_{y}
\end{array}\right] \\
& \mathbf{J}_{q}=\mathbf{I}_{3 \times 3}
\end{aligned}
$$

Moreover, one can write eq.(28) as:

$$
\dot{\mathbf{x}}=\mathbf{J} \dot{\mathbf{q}}
$$

In which

$$
\mathbf{J}=\mathbf{J}_{x}^{-1}
$$

\subsection{Singularity Analysis}

Algebraically, singularity deals with the rank deficiency of the associated Jacobian matrices. While geometrically, it is observed that the manipulator gains at least one additional uncontrollable DOF or loses one or a few DOF in singular points. The singularities encountered in parallel manipulators can be divided into three main groups [6]. The first type of singularity occurs when the manipulator reaches the boundary of its workspace. In such a configuration, different branches of the inverse kinematic problem meet, $\operatorname{det}\left(\mathbf{J}_{q}\right)$ vanishes and one actuator does not produce any motion of the EE.

At the second type of singularity, the EE can move in one or more directions and cannot resist against the force or torques in those directions while the actuators are locked. As opposed to the first one, this type of singularity occurs whenever different branches of the forward kinematic problem meet and $\operatorname{det}\left(\mathbf{J}_{x}\right)$ vanishes.

The third type of singularity occurs in the case that both types of the foregoing singularities occur, simultaneously [6].

Condition number of the Jacobian matrix is an index to measure the distance from singularity. It will increase in the vicinity of the singular points. The inverse of this index, namely Local Conditioning Index is commonly used for a measure of dexterity in robotic manipulators [7].

Tricept has a complex degree of freedom; therefore its condition number depends on the singular values of the dimensional in-homogeneous Jacobian. Here, we divide the Jacobian entries by units of length, thereby producing a new Jacobian that is dimensionally homogeneous. By multiplying the associated entries of the twist array to the same length, 
we made this array homogeneous, as well. This implies some sort of tradeoff between position and orientation components of the twist array.

\subsection{Weighted Factor Method}

Dividing the second and the third columns of the Jacobian matrix of Eq. 28 by a length and multiply the second and the third coordinates of the twist vector to the same length [8] leads to the following dimensionally homogeneous relation:

$$
\left[\begin{array}{ccc}
n_{l 1 z} & \frac{\left(\mathbf{R}\left(\mathbf{a}_{1}+\mathbf{d}\right) \times \mathbf{n}_{11}\right)_{x}}{l} & \frac{\left(\mathbf{R}\left(\mathbf{a}_{1}+\mathbf{d}\right) \times \mathbf{n}_{11}\right)_{y}}{l} \\
n_{l 2 z} & \frac{\left(\mathbf{R}\left(\mathbf{a}_{2}+\mathbf{d}\right) \times \mathbf{n}_{12}\right)_{x}}{l} & \frac{\left(\mathbf{R}\left(\mathbf{a}_{2}+\mathbf{d}\right) \times \mathbf{n}_{12}\right)_{y}}{l} \\
n_{l 3 z} & \frac{\left(\mathbf{R}\left(\mathbf{a}_{3}+\mathbf{d}\right) \times \mathbf{n}_{13}\right)_{x}}{l} & \frac{\left(\mathbf{R}\left(\mathbf{a}_{3}+\mathbf{d}\right) \times \mathbf{n}_{13}\right)_{y}}{l}
\end{array}\right]\left[\begin{array}{c}
\dot{c} \\
l \dot{\psi} \\
l \dot{\theta}
\end{array}\right]=\left[\begin{array}{c}
i_{1} \\
i_{2} \\
i_{3}
\end{array}\right]
$$

\section{WORKSPACE ANALYSIS}

In this section, we study the workspace of Tricept manipulator based on combination of analytical method and numerical one.

\subsection{Algorithm}

In order to generate the workspace of Tricept parallel manipulator, we divide the three dimensional $\psi-\theta-Z$ workspace of the moving platform into a series of subworkspaces that are parallel to $\psi-\theta$ plane. Then a numerical searching method is adopted to determine the boundary of the sub-workspaces. Finally, the volume of workspace is calculated quantitatively. The searching method adopted here is similar to the one used in [9].

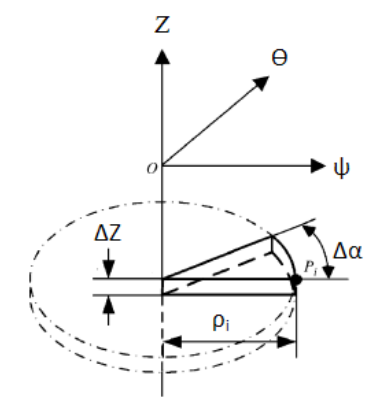

Fig. 2: Boundary points of a sub-workspace.

In the particular sub-workspace at elevation $Z_{i}$ (within the workspace), to determine the boundary of the sub-workspace one may find trajectories formed by the end of polar vector $\boldsymbol{\rho}_{i}$ rotating about $\mathrm{z}$ axis from 0 to $2 \pi$, (see Fig. 2). When the boundary point in the direction of $\boldsymbol{\rho}_{i}$ is found as $P_{i}(\rho \operatorname{Cos} \alpha, \rho \operatorname{Sin} \alpha, Z i)$; where $\rho_{i}$ is the distance between $\mathrm{Z}_{\mathrm{i}}$ and $P_{i}$, $\alpha$ will be increased by $\Delta \alpha$, and the next point will be found, similarly. The determination of point $P_{i}$ is based on the inverse kinematics of the Tricept. When searching the next boundary point $P_{i+1}$, we set the initial value of $\rho_{i+l}$ as $\rho_{i}$, and judge whether point $P_{i+l}$ is in 
the range of workspace; if yes, then increase $\rho_{i+1}$, if not, then decrease $\rho_{i+1}$ until point $P_{i+1}$ is on the boundary of the workspace. Once the boundary points in the sub-workspace are all searched out, $Z_{\mathrm{i}}$ will be decreased by $\Delta Z$, and the new searching will be performed again. Moreover, when $\alpha$ is increased by $\Delta \alpha$, the unit volume of the corresponding workspace can be expressed approximately as:

$$
d V=\frac{\Delta \alpha}{2 \pi} \pi \rho_{i}^{2} \Delta Z
$$

Therefore, the volume of the workspace can be calculated as:

$$
V=\sum_{Z_{i}=Z_{\min }}^{Z_{\max }} \sum_{\alpha=0}^{2 \pi} \frac{1}{2} \rho_{i}^{2} \Delta \alpha \Delta Z
$$

\subsection{Geometric Constraints}

There are some geometric constraints in the design process. These constraints are the upper and lower limits of actuators, spherical and universal joints, links lengths and platforms radiuses. It is simple to calculate the cone angle of joints $(\zeta)$ by using the geometric relations between actuators vector and EE pose. The geometric constraints of the Tricept robot, is given in Table 1.

Table 1: Geometric constraints of the Tricept manipulator.

\begin{tabular}{ccccc}
\hline $\begin{array}{c}\text { Actuator } \\
(\mathbf{m m})\end{array}$ & $\begin{array}{c}\boldsymbol{d} \\
(\mathbf{d e g})\end{array}$ & $\begin{array}{c}\boldsymbol{d} \\
(\mathbf{m m})\end{array}$ & $\begin{array}{c}\mathbf{b} \\
(\mathbf{m m})\end{array}$ & $\begin{array}{c}\mathbf{a} \\
(\mathbf{m m})\end{array}$ \\
$400-750$ & \pm 60 & $20-$ & $300-$ & $200-$ \\
& & 200 & 500 & 300 \\
\hline
\end{tabular}

\section{GA OPTIMIZATION}

One of the drawbacks of parallel manipulators is their limited workspace volume. Here, we apply Genetic algorithm for workspace volume optimization.

Objective Function:

For achieving the desired workspace with maximum volume the objective function defined as follow:

$$
V^{*}=\max (V)
$$

where $V$ and $V^{*}$ are workspace volumes with unit of $m m \cdot R a d^{2}$ and workspace volume without considering any constraints (like conditioning index) respectively which can be estimated by the foregoing algorithm.

All the parameters which play a role on the workspace volume are considered as the design parameters. They are the moving and base platform radiuses ( $a$ and $b$ ) and the upper part of passive link length $(d)$.

$$
\lambda=[a, b, d]^{\mathrm{T}}
$$


IIUM Engineering Journal, Vol. 12, No. 5, 2011: Special Issue -1 on Science and Ethics in Engineering

Therefore, the problem can be stated as:

$$
\begin{aligned}
& V^{*}=\operatorname{Max}\left(V\left(d, r_{a}, r_{b}\right)\right) \\
& \quad \text { Subject to: } \\
& 1-200<a<300,300<b<500, \quad 20<d<200 \\
& 2-400<\text { Actuator Length }(L)<750,-60<\zeta_{i}<60 \text { deg }
\end{aligned}
$$

This optimization problem is solved by GA and leads to the data given in Table 2 , in which the maximum workspace is $944.2176\left(\mathrm{~mm} . \mathrm{Rad}^{2}\right)$. Moreover, the workspace is illustrated in Fig. 3.

Table 2: Optimization results for maximum workspace.

\begin{tabular}{ccccc}
\hline $\begin{array}{c}\text { No. of } \\
\text { Iteration }\end{array}$ & $\begin{array}{c}V^{*} \\
\left(\mathrm{~mm}_{\mathrm{Rad}} \mathrm{Ra}^{2}\right)\end{array}$ & $\begin{array}{c}d \\
(\mathrm{~mm})\end{array}$ & $\begin{array}{c}a \\
(\mathrm{~mm})\end{array}$ & $\begin{array}{c}b \\
(\mathrm{~mm})\end{array}$ \\
\hline 51 & 944.2176 & 20 & 300.062 & 200 \\
\hline
\end{tabular}

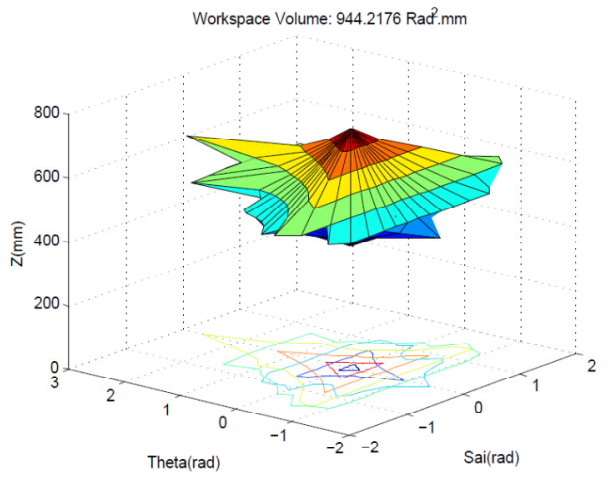

Fig. 3: Maximum workspace.

Finally, we evaluate the distance from singularity by means of local conditioning index throughout the workspace of the Tricept. This index for the optimized design of the Table II is within 0.57 and 0.61. Moreover, the index for different elevations is depicted in Fig. 4. 


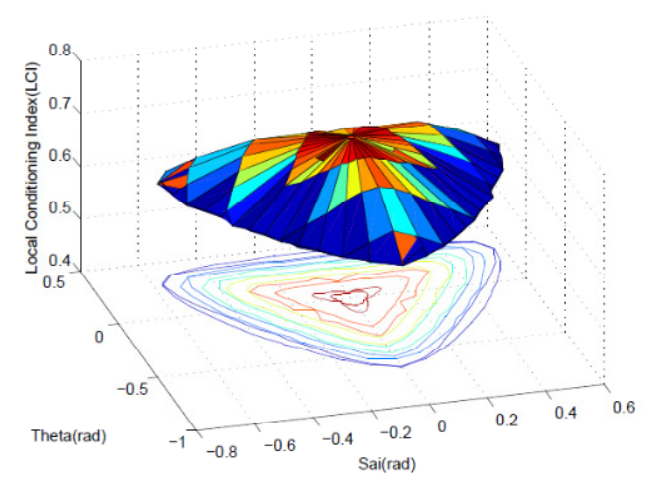

Fig. 4: Local conditioning Index in different elevations.

It is obvious from this figure that the design does not have any singular points within its workspace; therefore, it is well-conditioned.

\section{CONCLUSIONS}

In this paper the workspace optimization of Tricept has been performed. This parallel manipulator has a complex degree of freedom and has leaded to dimensional inhomogeneous Jacobian matrices. Therefore, we divided some entries of the Jacobian by units of length, thereby producing a new Jacobian that is dimensionally homogeneous. By multiplying the associated entries of the twist array to the same length, we made this array homogeneous as well. For the platform, the workspace was parameterized using some design parameters. Then, using GA method, the workspace was optimized subjects to some geometric constraints. Moreover, the evaluation of local conditioning index revealed the dexterity of the design.

\section{REFERENCES}

[1] J. Angeles, "Fundamentals of robotic mechanical systems," New York, USA: SpringerVerlag; 1997.

[2] J.-P. Merlet, "Parallel Robots,"Kluwer Academic Publishers, 2000.

[3] S.-D. Stan, V. Maties, R. Balan and C. Lapusan, "Optimization of a hexapod micro parallel robot using genetic algorithms," Innovations and Advanced Techniques in Systems, Computing Sciences and Software Engineering, pages 37-42, 2008.

[4] K.-E. Neumann. US patent 4,732,525, Mar. 22, 1988.

[5] B. Siciliano, "The Tricept robot: Inverse kinematics, manipulability analysis and closed-loop direct kinematics algorithm," Robotica, vol. 17, no. 4, pp. 437- 445, 1999.

[6] H. R. Mohammadi Daniali, P. J. Zsombor-Murray, and J. Angeles, "Singularity analysis of planar parallel manipulators" Mechanism and Machine Theory, vol. 30, no. 5, pp. 665-678, 1995.

[7] H. R. Mohammadi Daniali, P. J. Zsombor-Murray, and J. Angeles, "The isotropic design of two general classes of planar parallel manipulators" Journal of Robotic Systems, vol. 12, no. 12, pp. 795-805, 1995.

[8] M.A. Hosseini and H.R. M. Daniali, "Weighted local conditioning index of a positioning and orienting parallel manipulator", unpublished.

[9] J.A. Carretero, R.P. Podhorodeski, M.A. Nahon and C.M. Gosselin, "Kinematic analysis and optimization of a new three degree-of freedom spatial parallel manipulator," Journal of Mechanical Design, vol 122, no. 1, pp. 17-24, 2000. 